\title{
Preparing Future Teachers for the Development of Students' Emotional Intelligence
}

\author{
Svitlana H. Dubovyk ${ }^{1, \#, *}$, Alexander Ya. Mytnyk ${ }^{2, \#}$, Nataliia O. Mykhalchuk ${ }^{3, \#,}$ \\ Ernest E. Ivashkevych ${ }^{3, \#}$ and Nataliia O. Hupavtseva, ${ }^{3, \#}$
}

${ }^{1}$ Borys Grinchenko Kyiv University, Kyiv, Ukraine

${ }^{2}$ National Pedagogical Dragomanov University, Kyiv, Ukraine

${ }^{3}$ Rivne State University of the Humanities, Rivne, Ukraine

\begin{abstract}
Objective: This study deals with the issues of preparing future educators for the development of students' emotional intelligence. The study aims to identify the most important aspects of future teachers training in the framework of this task, to identify the main factors that should be paid attention to when training teachers, whose tasks in the future will include the development of emotional intelligence of school students.

Background: Particular attention is paid to the study of the training of teaching staff for the development of emotional intelligence in students with psychological disturbances. The object of the study is the branches of pedagogy of higher education aimed at educating qualified teaching staff that can effectively solve the tasks of developing the emotional intelligence of elementary school students.

Method: In the study, methods of system analysis of the subject matter are used, based on a detailed examination of the studies of the material available for research, with a qualitative analysis of all the collected information.

Results: Based on the conducted studies were formed recommendations on the training of teachers for future practical activities within the framework of the issues under consideration, which are summarised as follows: in training, attention should be paid to working with educational games, the task of which is to develop students' skills in identifying and evaluating emotions, their own and of students participating in the game, the study and analysis of works of classical literature, as a method of learning to think, analyse and develop the emotional sphere, training in the implementation of special exercises for the development of the emotional sphere.
\end{abstract}

Conclusion: The study has important applied value in terms of expanding the understanding of emotional intelligence and the need for its development, starting from the lower grades of high school.

Keywords: Emotional intelligence, pedagogy of higher education, pedagogical support, school development, professional-pedagogical activity.

\section{INTRODUCTION}

Modern pedagogical science pays close attention to the issues of relations that arise between the feelings and minds of students, the interpenetration of rational and emotional principles in the children's psyche. In this context, the problems of emotional intelligence and its development among students are of particular importance. First of all, this applies to representatives of the lower grades of secondary school. Also, the issues of training teachers for these educational institutions are related to this, which in the future will be capable of qualitatively solving the problems of educating students and developing their adequate emotional intelligence. Currently, emotional intelligence is attracting more and more attention of researchers, as it gives a person the opportunity, with the competent management of the emotional sphere, to positively influence its own adaptation in society and achieve the

*Address correspondence to this author at the Borys Grinchenko Kyiv University, Kyiv, Ukraine; Tel: +38044 272 1902; E-mail: s.dubovyk@tanu.pro

"These authors are equally contributed. tasks set in life. There is even a reasoned opinion among researchers that it is emotional intelligence that determines the future success of an individual in various areas of his life (social, professional and personal) with a share of $80 \%$. IQ in this context is allocated no more than $20 \%$ [1]. Accordingly, issues related to the development of emotional intelligence, starting from the elementary grades of high school, and the problems associated with them, the training of qualified pedagogical personnel who are able to solve such issues qualitatively.

It will be appropriate to define the concept of emotional intelligence. Researchers do not have a shared vision in the interpretation of this concept. There is an opinion that emotional intelligence can be interpreted as "the ability to understand and control their own and others' emotions" [2]. It is also noted that the concept in question is a complex psychic formation that has a personal and cognitive nature. Emotional intelligence is capable of "determining and identifying personal emotions and emotions of others, analysing the information received in order to apply it in everyday 
activities effectively. It is expressed in the direction of harmonising relations with others and solving problems of the rational management of emotions and feelings" [1]. The variety of definitions of this concept determines the difference in scientific approaches to the issue under consideration, as well as the problems of training specialists in the development of emotional intelligence in students.

Society as a whole and pedagogical activity, in particular, put forward a relatively wide range of requirements for the teacher as a specialist in his field. To this date, the following basic functions of a primary school teacher are legally designated: planning and implementation of the educational process; providing and supporting the education, upbringing and development of students in the educational environment and the family; creating an educational environment; reflection and professional selfdevelopment; conducting pedagogical research; providing methodological assistance to colleagues on the issues of training, development, upbringing and socialisation of primary school students; generalisation of own pedagogical experience and its presentation to the pedagogical community; assessment of the results of the work of primary school teachers of general secondary education schools [3]. It is worth noting that the establishment of a teacher does not take place immediately and his qualities, corresponding to the above requirements, are honed and improved throughout his professional career. However, even a beginner teacher at the very beginning of the work requires a complete immersion in the pedagogical process, a high-quality solution to all problems associated with teaching children and developing their abilities. Difficulties are inevitable, among which stand out: problems caused by professional incompetence and inability to solve educational problems, lack of an adequate level of communication with students, social problems [4].

In this regard, the issue of the necessity for highquality preparation of the future teacher to work with students in general and related to his preparation for the development of emotional intelligence of students, in particular, are clearly manifested. These issues are particularly relevant considering the presence in modern schools of a large number of students with severe psychological disturbances, with whom the teacher needs to find contact and work in terms of their further education and the development of their creative abilities in general and emotional intelligence in particular. The questions are complex, multifaceted and in general, going far beyond the scope of a single scientific study. Moreover, in recent years, in several CIS countries and Ukraine, in particular, the number of pedagogical universities has been reduced, and many teacher training systems have been recognised as ineffective in the current conditions. In addition, the very criteria for evaluating the effectiveness of the training of modern teachers raise questions from many scientists. Nevertheless, the issues of preparing future teachers for the development of students' emotional intelligence do not lose their relevance and require careful consideration both in the framework of scientific research and in the context of legislative norms related to improving the system of modern education.

\section{LITERATURE REVIEW}

In the modern education system, significant attention is paid to the training of future teachers in the scientific literature and society as a whole. So, Polezhaeva O.A., writes "Education is the most important condition for development, scientific progress and economic growth. Social development is directly related to the cultural and intellectual base of a single individual" [5]. At the same time, researchers note that improving the training of future teachers is one of the problems of higher education. First of all, it is required to increase the reputation of the profession, which has shaken noticeably during the time that has passed since the collapse of the USSR. In this regard, Berezhnaya I.F. indicates the need to create and conduct a targeted campaign in the media, pursuing the task of correcting the situation and creating a positive image of the teacher, especially in the eyes of future representatives of this profession [6]. Also, the author-researcher emphasises the importance of teachers' high competence in working with students and the need to create appropriate conditions to ensure such in their preparation. It is rightly noted that "the solution to this issue will determine in many respects who will work with our children, what teachers will enter the classes and what ideas they will pass on to the future generation" [6]. In this context, researchers note the importance of developing the emotional-volitional sphere of future teachers at the stage of their entry into the profession. Manoilova M.A. confirmed with experiments the relationship between the development of the will of teachers, their intelligence and various components that determine the effectiveness of their professional activities: orientation on the development of students, their performance, ability to partner, dialogue communication [7]. It is these qualities that should be developed by future teachers even at the 
stage of preparation for the profession, for a highquality solution to the problems of developing the emotional intelligence of students.

Salcido-Cibrián L. J., Ramos N. S., Jiménez Ó., Blanca M. J. in their study describe the impact of the "Consciousness and Emotional Intelligence Program" on experiment participants. A random sample of 89 people shows "the best results of participants who completed the program, among other subjects. Participants who completed the program showed improved health, empathy, and mental activity" [8]. This emphasises the importance of developing emotional intelligence and the need to prepare future teachers in the right way to solve such problems in communicating with students. At the same time, in research papers, the difficulty is noted in the formation of the emotional sphere of students in the modern education system. Kuznetsova K.S. writes "Even with the declared and ongoing innovation orientation the modern school cannot ensure the full development of the emotional sphere of students and the development of their emotional abilities. The existing training system helps to a small extent to create suitable conditions for the formation of future success in society, life adaptation, personal and professional growth. The main work is carried out to provide students with academic knowledge, while almost no attention is paid to the development of emotional intelligence" [9]. In turn, Osipova I.S. and Egorov V.S. in their studies provide specific recommendations on the design of students' emotional intelligence development programs. In general, in their opinion, such programs: 1) should be based on the basic methods of training sessions in youth groups; 2) take into account the individual characteristics of those involved and the level of their emotional intelligence; 3 ) include blocks with exercises designed to develop the private components of emotional intelligence; 4) include assignments for reading literary works of art and their written analysis; 5) include non-verbal and verbal exercises; 6) include the organisation of educational situations with the updating of mental reactions [10]. Researchers emphasise the importance of identifying the characteristics of emotional intelligence at the high school stage and its subsequent development. They draw attention to the fact that "the identification of such features will not only enrich psychological science but will also make it possible to formulate recommendations for counselling and professional selection in the future" [11].

Thus, in literature sources, there is a broad understanding of the issues of emotional intelligence and the possibilities and prospects of its development even at the secondary school stage. This only emphasises the importance of the issue of training qualified teaching staff to solve the problems of the qualitative development of the students' emotional intelligence.

\section{MATERIALS AND METHODS}

The study sets the task of examining the issues of training future teachers for the development of students' emotional intelligence. As part of the study, the work of domestic and foreign authors on the issues of emotional intelligence and its development is considered. Special attention is paid to the possibility of developing emotional intelligence in students with certain psychological disturbances and disorders. The main directions of research activity in the framework of the studied issue are identified, the dominant emphasis in assessing the problems of the development of emotional intelligence in general, as well as in high school students, especially those with psychological disturbances, are identified. From this area of research, a transition is being made to the study of the issues of training professional teachers who are able to qualitatively solve the development of emotional intelligence in the indicated categories of students.

The methodology of this study is based on a combination of a systematic method for analysing research developments within the considered area with a qualitative analysis of the collected materials. As indicated above, a significant amount of information was gleaned from the development of modern authors. They investigated the issues of emotional intelligence and the possibilities of its development in representatives of various age groups. A meticulous analysis of materials available within the framework of the declared topic is carried out: journal and book publications, dissertation research, devoted to studying the development of emotional intelligence of students in general and the training of qualified teaching staff capable of qualitatively solving the stated tasks. The perspectives of research in this direction, as well as various practical aspects of the activities of teachers conducting classes with students to develop their emotional intelligence, are assessed. Particular attention is paid to the issues of the work of teachers with the group of students endowed with psychological disturbances, indicated the exceptional features of this category of students and the related features of the pedagogical approach to their learning, designed to help achieve the tasks set in the learning process. A 
significant amount of information for the analysis was taken from the publications by foreign authors conducting research in a given direction. In order to facilitate the perception and create maximum conditions for an objective, high-quality perception of the studied information, the materials of the mentioned publications were translated into English. A thorough analysis of the entire array of collected and properly generalised data contributes to the creation of an objective picture of the study and the formation of appropriate conditions for the systematisation of the data and the formation of objective, independent conclusions. Based on the performed system analysis of all the information collected during this study, a qualitative analysis of the data is performed, the results and conclusions obtained during the research are formed, which objectively and logically summarise the results of this study. The main, dominant directions are established both in the development of students' emotional intelligence and in the training of teachers who are able to qualitatively solve the problems of developing the emotional intelligence of students in general and having psychological disorders in particular. The main factors that influence the processes of preparing teachers for work in this area are determined, specific recommendations for the development of pedagogical and educational programs are given, and specifics in pedagogical approaches to exposure with the aim of achieving the stated result for particular groups of students are indicated. In general, the methodology of this study is aimed at obtaining the most functional picture of the practical training of teachers who are able to qualitatively solve the problems of developing the emotional intelligence of students. The results of this study can be of great practical importance both for subsequent scientific developments in the framework of the declared thematic area and for practical activities for the preparation of relevant teaching staff. Also, the results obtained during the study can add understanding to the issues of practical training of teachers who are able to solve in practice the issues of developing emotional intelligence in students of complex learning groups, which seems extremely important for the subsequent professional orientation of these students, and their whole future life in general.

\section{RESULTS}

The development of students' emotional intelligence is an insufficiently studied area of the pedagogical activity. Therefore, much in this direction is still being mastered at the level of the initial experience, which has yet to be generalised and properly assessed. Nevertheless, a huge number of researchers in the field of psychology and social, interpersonal relations recognise the crucial importance of emotional intelligence in the life of an individual and, as a result, the need for its development, starting from the elementary grades of a comprehensive secondary school. Accordingly, the issues of training teachers who are able to solve such problems qualitatively come to the foreground. The issues under discussion are of particular importance because modern schools (Ukrainian, in particular) have a significant number of children with severe psychological disturbances. The teacher needs to be able to find contact with this category of students, to achieve their harmonious inclusion in the educational process so that such students do not feel any impairment or infringement. Based on the results of modern research within the framework of the stated topics, it seems advisable to begin the development of emotional intelligence of students with the development of it among future teachers themselves. In this regard, it is necessary to turn to the studies of recognised authors within the framework of this topic $[12,13]$. Studying the quality literature on this issue will contribute to the formation of future teachers' understanding of the issues of managing emotions, moods, habits and thoughts. Subsequently, all this will be of great importance when working with students in the framework of the direction stated in this study.

It is worth noting individually the features of the preparation of teachers to work with students who have psychological disturbances. Children with cognitive impairment account for $2.5 \%$ of the total number of primary school students [13]. The issues of correction of their emotional development raise several questions, in view of:

- $\quad$ an increase in the total number of such children and the insolubility of many problems of their development;

- a significant scatter of such students compared to others in individual and age-related indicators of the emotional sphere [13].

In such a situation, the teacher is required to be able to see and take into account typical individual characteristics of deviations in the development of such students and take them into account when organising training sessions. Accordingly, these factors should be taken into account when preparing future teachers for 
working with such children. This involves conducting special classes with future teachers at the stage of their education and publishing relevant guidelines for working with children with deviations in psychological development. Unfortunately, in the system of teacher training, such methodological developments are still sorely lacking. In addition, in the development of the students' emotional intelligence, especially at the elementary school stage, the teacher's playing activities with them are of great importance. Future educators should be taught the features of board games, such as: "Emotional Intelligence", "Telepath" in which the participant should show their own emotions and predict the emotions of other game participants, as well as learn to receive non-verbal signals from other game participants, try to guess their thoughts and feelings.

At the stage of preparing teachers for work with children with mental disabilities, as part of the development of their emotional intelligence, considerable attention should be paid to the study of works of classical literature with their in-depth, written analysis. Written works in the form of essays and compositions as part of what they read will contribute to the development of the emotional intelligence of the teachers themselves, in the first place. In addition, introducing a similar methodology in the future in their professional activities, teachers will receive a tool for assessing the emotional experiences of their students, manifested by what they read. Analysis of the works of classical literature in group classes with students will contribute to the development of their emotional sphere, ability to empathise with the heroes, and mentally analyse their actions. All this positively affects the development of the emotional intelligence of students in general. At the stage of preparing teachers for work with children, special attention should be paid to teaching special exercises for the development of emotional intelligence. Such exercises can be performed by the student both independently, with a partner or in a group. They contribute to the development of empathy among students, the ability to empathise and understand the feelings and pains of another. An example of such kind of exercise: a group of students (4-8 people) sit in a circle and take each other's hands. In perfect silence, closing their eyes, the entire group synchronously takes a breath of 4 counts, hold their breath for 4 counts and exhale for 4 counts. This is repeated for 3-5 minutes. After this, the hands are disconnected; the participants open their eyes and exchange their feelings and emotions from the exercise. Such verbal and non-verbal exercises will help teachers to expand their sphere of emotional perception in order to apply it in class with students successfully.

Special attention should be paid to the development of the psychological stability of teachers. Working with children with visible deviations of psychological development requires a great deal of endurance and patience from the teacher. Therefore, it is recommended to include special practices for the development of these qualities in the training program for future teachers. It can be meditative yoga practices or individually selected exercises for the development of psychological endurance. One of these exercises is sitting meditation, with the deepest breathing and complete silencing of thoughts for 4-5 minutes. Regular practice for several months already strengthens psychological stability and calms the nervous system. Thus, the issues of preparing future teachers for the development of the emotional intelligence of students in general and with psychological disturbances, in particular, are very complex and require careful study. The quality of their resolution and implementation in practice influences emotional health of both the teachers and students, as well as, in many ways, the future social-professional orientation of students and their future life.

\section{DISCUSSION}

The issues of preparing teachers for work in general and with students with disorders of psychological development in particular in the context of the development of emotional intelligence in them are largely debatable. The almost complete absence of scientific, methodological developments within the framework of this topic gives rise to many interpretations of the issue by researchers. At the same time, several authors, in particular, Shklyar N.V. note the relevance of the topic due to the increase in the number of children with psychological disturbances. The researcher writes, "The problem of teaching and raising children with developmental difficulties is gaining more urgency in terms of the increase in their number" [13]. Moreover, the significance of the very concept of emotional intelligence in the context of training, as a rule, is not disputed by the authors. So, Ahmeda Z., Asima M. and Pellitteri J., write "Emotional intelligence has been defined by studies as a developing field that affects academic performance" [14]. Moreover, the researchers emphasise the importance of the development of emotional 
intelligence of students and the need for quality training of professional teaching staff for its development in children. Stillman S. B., Stillman P., Martinez L., Freedman J., Leet C. note "Evaluation of the level of emotional intelligence of students is extremely important for improving their competencies, introducing programs for the development of emotional intelligence. The quality of student training in this area determines the effectiveness of the teacher" [15]. Turculeţ A., in his studies, describes experiments to evaluate the level of emotional intelligence among primary school teachers in 36 schools. The results of the study "... identify patterns between the level of emotional intelligence of a teacher and the quality of development of emotional intelligence of students by teacher, as well as the quality of his teaching activities in general" [16]. Thus, the importance of the emotional intelligence of the teachers themselves and the need for its development at the stage of preparation for professional activity is emphasised.

Researchers note that modern educators are often not ready for a quality solution to issues related to the development of emotional intelligence of students with psychological developmental deficiencies. So, Shklyar N.V. writes "... teachers do not pay enough attention to the problem of developing the emotional intelligence of students and need special advice themselves. Help is necessary because optimal conditions for the development of emotional intelligence in primary school students can be created only taking into account the individual characteristics of their emotional sphere" [13]. At the same time, Berezhnaya I.F., focuses on the role of the modern higher education system in the preparation of high-quality teaching staff for the development of students' emotional intelligence. The researcher writes: "In modern conditions, a classical university can and should become the foundation for the professional preparation of teachers for practical activities, research work aimed at the development of students in general and their emotional intelligence in particular" [6].

Foreign researchers also pay considerable attention to the development of emotional intelligence in students with psychological disabilities. So, a group of researchers composed of Nyarko F., Peltonen K, Kangaslampi S. and Punamäki R-L. pay attention to the fact that "the effect of stress on the mental health of adolescents is manifested in a decrease in the level of their emotional intelligence. A high level of stress in everyday life leads to a decrease in the emotional intelligence of young people and entails mental disorders" [17]. Scientists focus on the need to limit stress on students in their daily lives, as the most important factor in the development of their subsequent emotional intelligence and prevent the progression of psychological disturbances. Studies by other authors reveal the relationship between students' emotional intelligence with their psychological state and social orientation. Salavera C., Usán P. and Teruel P., according to the results of testing a number of high school students, revealed the connection of their emotional intelligence with contextual problems (in school, family and with classmates). Scientists note "contextual problems negatively affect the students' emotional intelligence, their academic results and social functioning" [18]. A teacher should pay special attention to working with such children in terms of developing their emotional intelligence and improving learning results.

The opinions of researchers on the issues of preparing teachers for the development of students' emotional intelligence are diverse, which only emphasises the scale of the issue and its importance, in the context of various aspects of the upbringing of the younger generation. Further research in this direction will be able to complement and expand existing ideas on this issue significantly.

\section{CONCLUSION}

The study of issues related to the preparing future teachers for the development of students' emotional intelligence, with an emphasis on the category with psychological development disorders, led to the following conclusions. Particular attention in the training of future teachers should be given to the development of the emotional intelligence of themselves, in combination with the development of their emotional and psychological stability. In this regard, it seems advisable in the course of preparation to focus on the study of works of classical literature and their in-depth analysis, as a way of developing the emotional intelligence of future teachers. In preparation for working with students with persistent psychological disturbances, it is recommended that they develop special exercises for group exercises to form empathy in students, the ability to empathise and capture the emotions of others involved. Group work can significantly improve the results in the development of emotional intelligence of those who are endowed with persistent psychological disturbances and will help to improve their further social adaptation. It is also recommended to pay attention to the development of 
future teachers' skills in working with board games aimed at developing the emotional intelligence of students. Similar classes have already shown good practical results when working with students who have persistent psychological disorders, and therefore can be recommended for use in the future. In addition, in the training of future teachers, special attention should be paid to the development of their ability to relax, for which it is recommended that the practice of mastering meditation, as a way to stabilise the psyche.

In general, it should be recognised that the issues of training future teachers for work in the direction of developing emotional intelligence in students are multifaceted, especially in the context of working with the category of students with psychological disturbances. Numerous studies in this direction can significantly enrich the accumulated body of knowledge and expand ideas about the development of the emotional intelligence of students in general and groups with psychological development disorders in particular.

\section{ACKNOWLEDGEMENTS}

None.

\section{REFERENCES}

[1] Kuznetsova KS. A model of pedagogical support for students in the process of developing emotional intelligence. Bulletin of PAGS 2011; 1: 125-130.

[2] Larina AT. Emotional intelligence. ANI: Pedagogy and Psychology 2016; 5(3): 275-278.

[3] Professional standard "Primary school teacher". 2018. Available at: http://search.ligazakon.ua/l_doc2.nsf/link1/info/ FN045030.html

[4] Konovalova IV. Features of professional adaptation of young professionals in educational institutions. Psychologist at School 2000; 1-2: 172-177.

[5] Polezhaeva OA. Modern aspects of professional training of students in the framework of teaching practice. Young Scientist 2012; 5: 482-485.
[6] Berezhnaya IF. Vocational training of future teachers at a classical university. Bulletin of the Voronezh State Technical University 2014; 6: 186-190.

[7] Manoilova MA. The development of emotional intelligence of future teachers. Pskov: PSPI, 2004.

[8] Salcido-Cibrián LJ, Ramos NS, Jiménez Ó, Blanca MJ. Mindfulness to regulate emotions: The mindfulness and emotional intelligence program (PINEP) and its adaptation to a virtual learning platform. Complementary Therapies in Clinical Practice 2019; 8: 176-180. https://doi.org/10.1016/j.ctcp.2019.07.003

[9] Antinienė D, Lekavičienė R, Psychological and physical wellbeing of Lithuanian youth: Relation to emotional intelligence. Medicina 2017; 4: 277-284. https://doi.org/10.1016/j.medici.2017.05.008

[10] Osipova IS, Egorov VS. Peculiarities of the emotional intelligence of schoolchildren and students of various professional types. Bulletin of the Mordovian University 2011; 2: 66-68.

[11] Goleman D. Emotional Intelligence. Moscow: Mann Ivanov and Ferber 2018

[12] Arden D. Taming Amygdala and other brain training tools. Moscow: Mann Ivanov and Ferber, 2018.

[13] Shklyar NV. The study of the characteristics of the emotional sphere of primary schoolchildren with impaired intelligence in order to optimise the educational process. Bulletin of the Far Eastern State Civil Aviation Administration 2011; 1/2: 102-117.

[14] Ahmeda Z, Asima M, Pellitteri J. Emotional intelligence predicts academic achievement in Pakistani management students. The International Journal of Management Education 2019; 7: 286-293. https://doi.org/10.1016/j.jime.2019.04.003

[15] Stillman SB, Stillman P, Martinez L, Freedman J, Leet C. Strengthening social emotional learning with student, teacher, and school wide assessments. Journal of Applied Developmental Psychology 2018; 3-4: 71-92. https://doi.org/10.1016/j.appdev.2017.07.010

[16] Turculeţ A. Teachers for the 21st Century. Will Emotional Intelligence Make the Difference? Procedia - Social and Behavioral Sciences 2017; 5: 990-995. https://doi.org/10.1016/j.sbspro.2015.02.188

[17] Nyarko F, Peltonen K, Kangaslampi S, Punamäki R-L. Emotional intelligence and cognitive skills protecting mental health from stress and violence among Ghanaian youth. Heliyon 2020; 5: 185-192. https://doi.org/10.1016/j.heliyon.2020.e03878

[18] Salavera C, Usán P, Teruel P. Contextual problems, emotional intelligence and social skills in Secondary Education students. Gender differences. Annales Médicopsychologiques, Revue Psychiatrique 2019; 3: 223-230. https://doi.org/10.1016/j.amp.2018.07.008

\section{DOI: https://doi.org/10.6000/2292-2598.2020.08.03.20}

\section{(c) 2020 Dubovyk et al.; Licensee Lifescience Global.}

This is an open access article licensed under the terms of the Creative Commons Attribution Non-Commercial License (http://creativecommons.org/licenses/by-nc/3.0/) which permits unrestricted, non-commercial use, distribution and reproduction in any medium, provided the work is properly cited. 